\title{
The Effects of Lidocaine on Reperfusion Ventricular Fibrillation During Coronary Artery - Bypass Graft Surgery
}

\author{
Ahmet Mahli* and Demet Coskun \\ Department of Anaesthesiology and Reanimation, \\ Gazi University Faculty of Medicine, Ankara, \\ Turkey
}

\section{Introduction}

Myocardial protection with cardioplegia has resulted in significant improvement in the outcomes of cardiopulmonary bypass (CPB) in coronary artery - bypass graft (CABG) procedure. However, subendocardial damage created by ischemic injury still remains a source of morbidity and mortality associated with CABG (1). Ventricular fibrillation (VF) occurring after releasing of aortic cross-clamp in the reperfusion phase of CABG surgery (reperfusion VF) is very common (74-96 \%) (1-5). This complication is considered to be related with ischemia-induced increases in reentry and automaticity as well as the possibility of reperfusion injury (6-8). Reperfusion VF may adversely affect coronary blood flow and increase ventricular wall tension, which causes a further depletion of myocardial energy reserves in an energydepleted myocardium (2). It is estimated that reperfusion VF occurs as a result of increased myocardial wall stress and oxygen consumption besides diminished subendocardial blood flow and intramyocardial acidosis (9-12). Additional myocardial injury following defibrillation by direct current countershocks may worsen this situation $(13,14)$. Therefore, it would be helpful for the patients' recovery after the CABG (15).

VF developing in reperfusion phase of CPB generally responds to defibrillation. Obstinate or recurrent VF increases myocardial oxygen demand, unfortunately resulting in ventricular dilatation. Furthermore, the ventricular relaxation creates irreversible myocardial injury. When heart remains in VF, it is necessary to recheck blood gases, electrolytes, and temperature. Lidocaine, a class Ib antiarrhythmic, is administered at a dose of 1 to $2 \mathrm{mg} \mathrm{kg}-1$ before repeated direct current defibrillation is attempted. Occasionally, beta blockers such as esmolol and metoprolol, class II antiarrhythmics and amiodarone, a class III antiarrhythmic are added in order to treat intractable VF or ventricular tachycardia (16). A previous study reported that in patients with persistent VF during weaning from CPB in cardiac surgery for heart diseases with left ventricular hypertrophy, amiodarone was a reasonable option (17).

Lidocaine, which is a local anaesthetic in amid group, acts as an antiarrythmyhic agent and it is classified in class $\mathrm{Ib}$. By binding $\mathrm{Na}^{+}$channels, lidocaine alters membranous conductivity

${ }^{*}$ Corresponding Author 
of cations. Lidocaine decreases depolarisation plateau of phase 4 and enhances diastolic electrical flow threshold in Purkinje fibers $(18,19)$. Lidocaine increases VF threshold, but this effect is directly related with plasma concentrations of lidocaine (20).

Although lidocaine is known to reduce VF incidence and defibrillation demand, the mechanism is not clearly understood yet. However, it is proved to be appropriate in the treatment of ventricular ectopic premature beats (18-21). In myocardial ischemic conditions, lidocaine has been shown to turn unidirectional blocking zones and slow conduction in ischemic zones to complete blocking areas (22). Another possible mechanism could be explained by inhibitory effect of lidocaine on $\mathrm{Na}^{+}$intake and membrane depolarisation such that cardiac arrest occurs when they are inhibited (23). As a result, the energy is kept away from electromechanical activity thus proceeding more accurate recovery for the heart. In addition to that local anaesthetics, lidocaine can block slow $\mathrm{Ca}^{++}$channels and $\mathrm{Ca}^{++}$channels of sarcoplasmic reticulum $(24,25)$.

Lidocaine has previously been added to cardioplegic solutions in order to prevent reperfusion VF (see table 1). When $500 \mathrm{mg} \mathrm{L}^{-1}$ of lidocaine was added to a crystalloid solution, there was a significant decrease in the incidence of $\mathrm{VF}$, but a higher percentage of atrio-ventricular (AV) block was also observed (4-12,14,26). Baraka et al. (13) showed that the incidence of reperfusion VF can be markedly reduced, from $93 \%$ to $42 \%$, with the addition of $100 \mathrm{mg} \mathrm{L}^{-1}$ of lidocaine to a crystalloid cardioplegic solution without an increase of the incidence of AV block. Wallace and Baker (2) repeated a similar study and reported that the incidence of reperfusion VF is reduced from $63 \%$ to $42 \%$ with the addition of $100 \mathrm{mg} \mathrm{L}^{-1}$ of lidocaine to a crystalloid cardioplegic solution. They noted that a higher proportion of the patients who developed reperfusion VF with lidocaine cardioplegia underwent spontaneous defibrillation (30\% versus $11 \%$ ), even though this was not statistically significant. On the other hand, different from the above mentioned study (13), they stated that the incidence of AV block necessitating ventricular pacing to separate from CPB was significantly higher in the lidocaine treated group $(44 \%)$ as compared with the control group (20\%). Sellevold et al. (27) added procaine instead of lidocaine in cardioplegic solutions to be able to observe the efficiency in post-ischemic rhythm disturbances, and they showed that cardioplegia with procaine $(1 \mathrm{mM})$ stabilised post-ischemic arrhythmia without any reverse effect.

Meta-analyses suggested that prophylactic lidocaine use reduces VF but increases mortality rates after acute myocardial infarction. Although its use may not be associated with increased mortality rates, the prophylactic lidocaine use, in fact, has decreased with the advent of thrombolysis, and the routine use of prophylactic lidocaine in acute myocardial infarction is not recommended $(28,29)$. In another study, lidocaine appears to be effective in converting no more than $20 \%$ of stable ventricular tachycardias (30).

In some investigations, the possible effect of lidocaine on autonomic cardiac control in humans was studied. Aidonidis et al. (31) found that in anaesthetized dogs, there was marked attenuation of cardiac sympathetic nervous activity by lidocaine which slightly altered efferent cardiac sympathetic nervous activity in the course of acute myocardial ischemia and reperfusion, but significantly increased it during VF. Abramovich et al. (32) showed that lidocaine has a consistent and significant parasympatholytic effect on the human heart in healthy volunteers as well as in patients in the acute phase of myocardial infarction. 


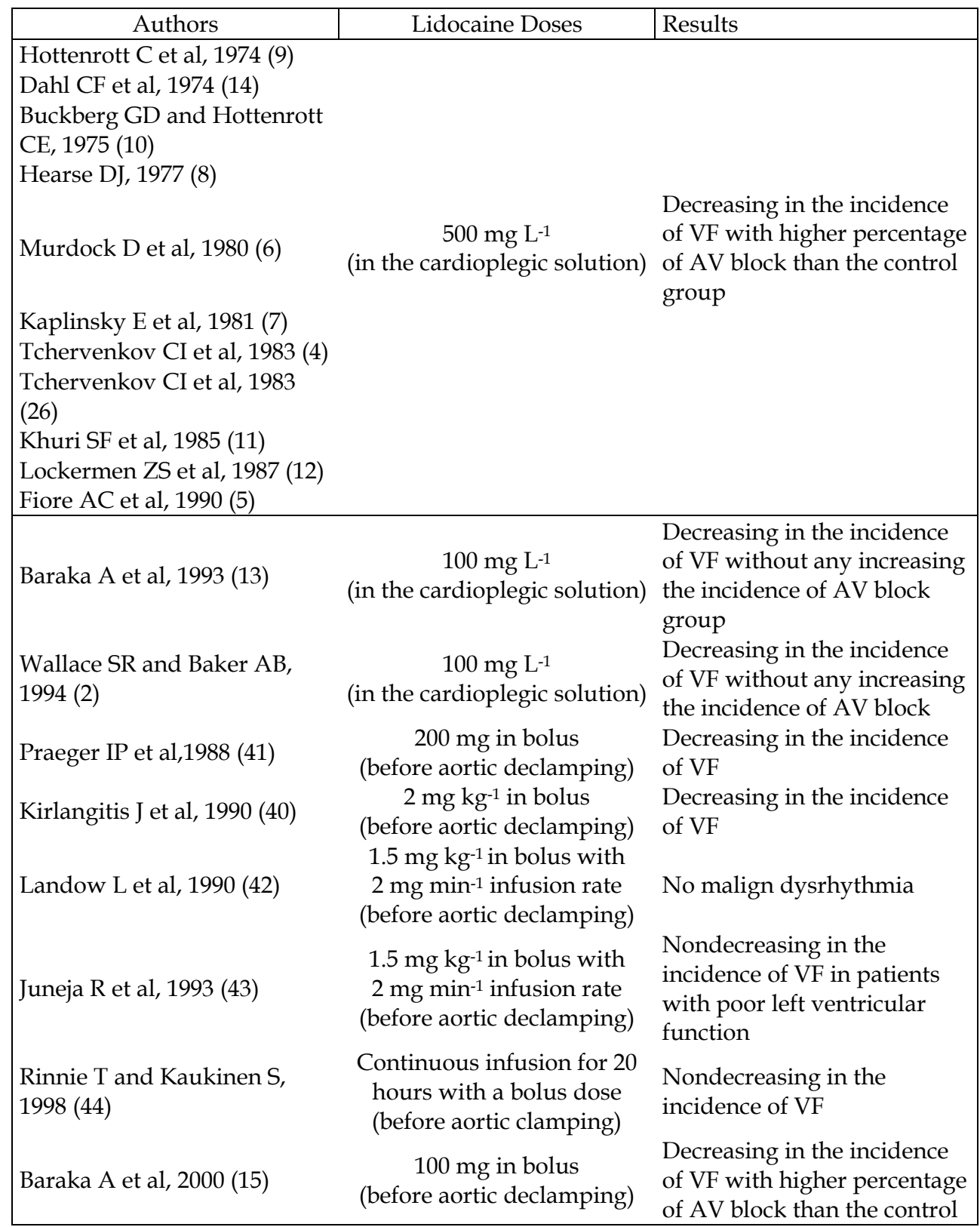

Table 1. The results of the studies about lidocaine use to reperfusion VF

Despite the theoretical advantages of lidocaine for the treatment of VF in the cardiopulmonary resusitation, it is well recognized that lidocaine can increase defibrillation threshold (33-36). Lidocaine has not been considered to have a substantial value in the 
majority of cases of VF because of not only its potential to increase the defibrillation threshold, but also its negative inotropic activity. Its use is probably best reserved for cases of persistently recurring VF after electrical defibrillation, particularly in association with reperfusion occurring after heart surgery $(34,37,38)$.

Hottenrott et al. (9) showed the augmentation of coronary blood flow to a sufficient rate towards increased energy demand in normal heart and in normothermic condition. They reported that redistribution occurs to keep endocardial / epicardial blood flow proportion. However, in hypertrophied and distended hearts and if a low aortic perfusion pressure exists, coronary blood flow will not be enough to meet increased oxygen consumption and this aspect can be explained by showing diminished coronary sinus $\mathrm{pH}$, increased lactate levels and $\mathrm{K}^{+}$concentrations. In patients with severe coronary artery stenosis, the occurrence of VFs aggravates subendocardial ischemic injury in detoriated left ventricle.

Khuri et al. (11) reported the adverse effect of VF despite venting of heart and hypothermic conditions in reperfusion state of $\mathrm{CPB}$, using continuous intraoperative intramyocardial $\mathrm{pH}$ monitoring technique.

Dahl et al. (14) demonstrated myocardial necrosis due to defibrillation in dogs and they proved the relation between the width of pedals and the frequency of defibrillation on myocardial injury. If the pedals are small or the frequency is scarce between defibrillations, the intensity of injury will be greater.

Manolis et al. (39) compared the efficiency and safety of lidocaine and tocainide given intravenously in patients with arrhythmia following cardiac surgery. They found that the drugs were both efficient, and there was not any statistical difference between these two drugs. In their study, they had administered $100 \mathrm{mg}$ lidocaine in bolus before $60 \mathrm{mg}$ infusion for 15 minutes. The infusion had been continued in a dose of $1.4 \mathrm{mg} \mathrm{min}^{-1}$ and the blood level had been found to be 1-4 $\mathrm{mg} \mathrm{L}^{-1}$.

Kirlangitis et al. (40) compared the efficacy of bretylium (10 mg kg-1), lidocaine (2 mg kg-1) and (as placebo) saline to prevent or to reduce VF incidence during reperfusion phase after aorta declamping. VF was seen $91 \%$ with saline, $64 \%$ with lidocaine and $36 \%$ with bretylium. The need for defibrillation was found lower with lidocaine and bretylium than saline group, but among two drugs they did not find any significant differences.

Praeger et al. (41) showed that the incidence of VF was reduced to less than $33 \%$ with treatment with $200 \mathrm{mg}$ of lidocaine intravenously 3 minutes before aortic declamping. In patients who had serum potassium levels that were higher than $5.1 \mathrm{mEq} / 1$ and treated with lidocaine before aortic delamping, the incidence of VF decreased to less than $15 \%$.

Landow et al. (42) administered $1.5 \mathrm{mg} \mathrm{kg}^{-1}$ lidocaine in bolus with $2 \mathrm{mg} \mathrm{min}^{-1}$ infusion rate before aorta declamping. In more than $50 \%$ of the patients, lidocaine serum levels were found to be in sub-therapeutic borders, but free lidocaine levels were within therapeutic limits. During this study, they didn't realise any malign dysrhythmia. Following this study, Juneja et al. (43) performed another study using similar lidocaine doses and reported that in patients with poor left ventricular function, prophylactic lidocaine did not reduce ventricular arrhythmias after CABG surgeries. 
Rinne and Kaukinen (44) studied the effect of an intravenous bolus of lidocaine given before clamping the aorta, which was followed by a continuous infusion for as long as 20 hours. They did not observe any increase in cardiac protection as evidenced by the analysis of serum troponin concentration and serum creatine kinase $\mathrm{MB}$ activity and by the electrocardiogram. They did not report any decrease in the incidence of reperfusion VF.

Baraka et al. (15) showed that the incidence of reperfusion VF could be significantly decreased without any increase in the incidence of AV block with the administration of a bolus of $100 \mathrm{mg}$ of lidocaine by way of the pump 2 minutes before the release of the aortic cross-clamp. In this study, the better cardiac output after weaning from CPB in the lidocaine group versus the control group was noted. They suggested that the result might be explained by the significant decrease of reperfusion VF in the lidocaine group (11\% versus $70 \%)$.

\section{Conclusion}

We concluded that following the CABG surgery, the incidence of reperfusion VF is quite high. During the CABG surgery, as a prophylactic measure, the administration of lidocaine at a dose of 1 to $2 \mathrm{mg} \mathrm{kg}^{-1}$ before releasing the aortic cross-clamp can decrease the incidence of reperfusion VF. However, because of the risk of AV block with using lidocaine, we believe that in patients with persistent VF and also with left venricular hypertrophy or dysfunction, the use of other anti-arrhythmic drugs would be more helpful for defibrillation.

\section{References}

[1] Fall SM, Burton NA, Graeber GM, Head HD, Lough FC, Albus RA, Zajtchuk R. Prevention of ventricular fibrillation after myocardial revascularization. Ann Thorac Surg 1987; 43:182-4.

[2] Wallace SR, Baker AB. Incidence of ventricular fibrillation after aortic cross- clamp release using lignocaine cardioplegia. Anaesth Intensive Care 1994; 22: 442-6.

[3] Curling PE, Nagle D, Zeidan JR, Kaplan JA. Effects of lidocaine, propranolol and bretylium on reperfusion dysrhythmias. Anesthesiology 1981; 55: A52.

[4] Tchervenkov CI, Symes JF, Wynands JE. Lidocaine as an adjunt to high potassium cardioplegia: a prospective randomized clinical trial. Surg Forum 1983; 34: 319-21.

[5] Fiore AC, Naunheim KS, Taub J, Braun P, McBride LR, Pennington DG, Laiser GC, Willman VL, Barner HB. Myocardial preservation using lidocaine blood cardioplegia. Ann Thorac Surg 1990; 50: 771-5.

[6] Murdock D, Loeb JB, Euler DE, Randal WC. Electrophysiology of coronary reperfusion and mechanism for reperfusion arrhythmia. Circulation 1980; 61: 175-82.

[7] Kaplinsky E, Ogawa S, Michelson EL, Dreifus LS. Instantaneous and delayed ventricular arrhythmias after reperfusion of acutely ischemic myocardium: Evedince for multiple mechanisms. Circulation 1981; 63: 333-40.

[8] Hearse DJ. Reperfusion of the ischemic myocardium. J Mol Cell Cardiol 1977; 9: 605-16.

[9] Hottenrott C, Maloney JV, Buckberg G. Studies of effects of ventricular fibrillation on the adequacy of regional myocardial flow. Part III. Mechanisms of ischemia. J Thorac Cardiovasc Surg 1974; 68: 634-45. 
[10] Buckberg GD, Hottenrott CE. Ventricular fibrillation: its effect on myocardial flow, distribution and performance. Ann Thorac Surg 1975; 20: 76-85.

[11] Khuri SF, Marston WA, Josa M, Braunwald NS, Cavanaugh AC, Hunt H, Barsamian EM. Observations on 100 patients with continuous intraoperative monitoring of intramyocardial $\mathrm{pH}$ : the adverse effects of ventricular fibrillation and reperfusion. J Thorac Cardiovasc Surg 1985; 89: 170-82.

[12] Lockermen ZS, Rose DM, Cunningham JN, Lichstein E. Repefusion ventricular fibrillation during coronary artery bypass operations and ist association with postoperative enzyme release. J Thorac Cardiovasc Surg 1987; 93: 247-52.

[13] Baraka A, Hirt N, Dabbous A, Taha S, Rouhana C, el-Khoury N, Ghabash M, Jamhoury M, Sibaii A. Lidocaine cardioplegia for prevention of reperfusion ventricular fibrillation. Ann Thorac Surg 1993; 55: 1529-33.

[14] Dahl CF, Ewy GA, Warner ED, Thomas ED. Myocardial necrosis from direct current countershock. Circulation 1974; 50: 956-61.

[15] Baraka A, Kawkabani N, Dabbous A, Nawfal M. Lidocaine for prevention of reperfusion ventricular fibrillation after release of aortic crosss-clamping. Journal of Cardiothoracic and Vascular Anesthesia 2000; 14: 531-3.

[16] Shanewise JS, Hines RL, Kaplan JA. Discontinuing cardiopulmonary bypass. In: Kaplan JA, Reich DSN, Lake CL, Konstadt SN (eds). Kaplan's Cardiac Anesthesia, 5th ed. Philadelphia: Elseiver Science, WB Saunders, 2006: 1024-5.

[17] Morita Y, Mizuno J, Yoshimura T, Morita S. Efficacy of amiodarone on refractory ventricular fibrilation resistant to lidocaine and cardioversion during weaning from cardiopulmonary bypass in aortic valve replacement for severe aortic stenosis with left ventricular hypertophy. J Anesth 2010; 26: 761-4.

[18] Weld FM, Bigga JT . The effect of lidocaine on diastolic transmembrane currents determining pacemaker depolarization in cardiac purkinje fiber. Circ Res 1976; 38: 203-8.

[19] Carmeliet E, Saikawa T. Shortenings of the action potential and reduction of pacemaker activity by lidocaine, quinidine and procainamide in sheep cardiac purkinje fibers. An effect on Na and K currents? Circ Res 1982; 50: 257-72.

[20] Schinittger I, Griffin JC, Hall RJ, Meffin PJ, Winkle RA. Effects of tocainide on ventricular fibrillation threshold. Comparison with lidocaine. Am J Cardiol 1978; 42: 76-81.

[21] Tosaki A, Balint S, Szekeres L. Protective effect of lidocaine against ischemia and reperfusion-induced arrhythmias and shifts of myocardial sodium, potassium, and calcium content. J Cardiovasc Pharmacol 1988; 12: 621-8.

[22] Cardinal R, Janse MJ, van Eeden I, Werner G, dAlnoncourt CN, Durrer Dl. The effects of lidocaine on intracellular and extracellular potentials, activation, and ventricular arrhythmias during acute regional ischemia in the isolated porcine heart. Circ Res 1981; 49: 792-806.

[23] Lee AG. Model of action of local anaesthetics. Nature 1976; 262: 545-8.

[24] Almers W, Best PM. Effects of tetracaine on displacement currents and contraction of frog skeletal muscle. J Physiol 1976; 262: 583-611.

[25] Chapman RA, Miller DJ. The effects of caffeine on the contraction of the frog heart. J Physiol 1974; 242: 589-613. 
[26] Tchervenkov CI, Wynands JE, Symes JF, Malcolm ID, Dobell AR, Morin JE. Electrical behavoir of the heart following high potassium cardioplegia. Ann Thorac Surg 1983; 36: 314-9.

[27] Sellevold OF, Berg EM, Levang OW. Procaine is effective for minimizing postischemic ventricular fibrillation in cardiac surgery. Anesth Analg 1995; 81: 932-8.

[28] Alexander JH, Granger CB, Sadowski Z, Aylward PE, White HD, Thompson TD, Califf RM, Topol EJ. Prophylactic lidocaine use in acute myocardial infarction: incidence and outcomes from tow international trials. Am Heart J 1999; 137: 799-805.

[29] Sadowski ZP, Alexander JH, Skrabucha B, Dyduszynski A, Kuch J, Nartowicz E, Swiatecka G, Kong DF, Granger CB. Multicenter randomized trial and a systematic overview of lidocaine in acute myocardial infarction. Am Heart J 1999; 137: 792-8.

[30] Singh BN. Acute management of ventricular arrhythmias: role of antiarrhythmic agents. Pharmacotherapy 1997; 17: 56-64.

[31] Aidonidis I, Brachmann J, Seller H, Demowsky K, Czachurski J, Kübler W. Cardiac sympathetic nervous activity during myocardial ischemia, reperfusion and ventricular fibrillation in the dog-effects of intravenous lidocaine. Cardiology 1992; 80: 196-204.

[32] Abramovich Sivan S, Bitton Y, Karin J, David D, Akselrod S. The effects of lidocaine on cardiac parasympathetic control in normal subjects and in subjects after myocardial infarction. Clin Auton Res 1996; 6: 313-9.

[33] Baskett PJF. Advances in cardiopulmonary resusitation. Br J Anaesth 1992; 69: 182-93.

[34] Weaver WD, Fahrenbruch CE, Johnson DD, Hallsrom AP, Cobb LA, Copass MK. Effect of epinephrine and lidocaine therapy on outcome after cardiac arrest due to ventricular fibrillation. Circulation 1990; 82: 2027-34.

[35] Ujhelyi MR, Schur M, Frede T, Bottorff MB, Gabel M, Markel ML. Mechanism of antiarrhythmic drug-induced changes in defibrillation threshold: role of potassium and sodium channel conductance. J Am Coll Cardiol 1996; 27: 1534-42.

[36] Ujhelyi MR, Sims JJ, Miller AW. High- dose lidocaine does not affect defibrillation efficacy: implication for defibrillation mechanisms. Am J Physiol 1998; 274: 1113-20.

[37] Lake CL, Kron IL, Mentzer RH, Crampton RS. Lidocaine enhances intraoperative ventricular fibrillation. Anesth Analg 1986; 65: 337-41.

[38] Fujita Y, Endoh S, Yasukawa T, Sari A. Lidocaine increases the ventricular fibrillation threshold during bupivacaine-induced cardiotoxicity in pigs. Br J Anaesth 1998; 80: 218-22.

[39] Manolis AS, Smith E, Payne D, Rastegar H, Cleveland R, Estes NA 3d. Randomized double-blind study of intravenous tocainide versus lidocaine for suppression of ventricular arrhythmias after cardiac surgery. Clinical Cardiology 1990; 13: 177-81.

[40] Kirlangitis J, Middaugh R, Knight R, Goglin W, Helsel R, Grishkin B, Briggs R. Comparison of bretylium and lidocaine in the prevention of ventricular fibrillation after aortic cross-clamp release in coronary artery bypass surgery. J Cardiothorac Anesth 1990; 4: 582-7.

[41] Praeger IP, Kay RH, Moggio R, Somberg E, Pooley R, Sarabu M, Sanshaia V, Kubai K, Kumar V, Reed GE. Prevention of ventricular fibrillation after aortic declamping during cardiac surgery. Clinical Investigation 1988; 15: 98-101. 
[42] Landow L, Wilson J, Heard SO, Townsend P, VanderSalm TJ, Okike ON, Pezzella TA, Pasque M. Free and total lidocaine levels in cardiac surgical patients. J Cardiothorac Anesth 1990; 4: 340-7.

[43] Juneja R, Mehta Y, Trehan N. Prophylactic lidocaine hydroclorid dose not reduce ventricular arrhymias after CABG in patients with poor left ventricular function. Indian Heart J. 1993; 45: 483-7.

[44] Rinnie T, Kaukinen S. Does lidocaine protect the heart during coronary revascularisation. Acta Anaesthesiol Scand 1998; 42: 936-40. 


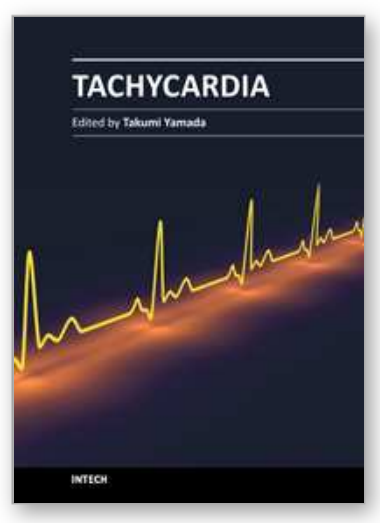

\author{
Tachycardia \\ Edited by Prof. Takumi Yamada
}

ISBN 978-953-51-0413-1

Hard cover, 202 pages

Publisher InTech

Published online 30, March, 2012

Published in print edition March, 2012

Heart rates are normally controlled by a natural pacemaker, the sinus node, and normal heart rhythm is called sinus rhythm. Tachycardia is defined as a faster heart rhythm than normal sinus rhythm. Tachycardias can cause symptoms such as palpitations, chest pain, shortness of breath and fatigue, which reduce the quality of life. Fast tachycardias can cause hemodynamic collapse and sudden cardiac death. The causes, mechanisms, and origins of tachycardias are various. The diagnosis of tachycardias is made by electrocardiograms and electrophysiological testing. Tachycardias can be managed and treated by pharmacological and nonpharmacological approaches. This book covers these concerns from basic and clinical points of view and will lead to a further understanding and improvement in the clinical outcomes of tachycardias.

\title{
How to reference
}

In order to correctly reference this scholarly work, feel free to copy and paste the following:

Ahmet Mahli and Demet Coskun (2012). The Effects of Lidocaine on Reperfusion Ventricular Fibrillation During Coronary Artery - Bypass Graft Surgery, Tachycardia, Prof. Takumi Yamada (Ed.), ISBN: 978-953-51-0413-1, InTech, Available from: http://www.intechopen.com/books/tachycardia/the-effects-of-lidocaine-on-reperfusionventricular-fibrillation-in-coronary-artery-bypass-graft-sur

\section{INTECH}

open science | open minds

\section{InTech Europe}

University Campus STeP Ri Slavka Krautzeka 83/A 51000 Rijeka, Croatia Phone: +385 (51) 770447 Fax: +385 (51) 686166 www.intechopen.com

\section{InTech China}

Unit 405, Office Block, Hotel Equatorial Shanghai

No.65, Yan An Road (West), Shanghai, 200040, China 中国上海市延安西路65号上海国际贵都大饭店办公楼 405 单元 Phone: +86-21-62489820

Fax: $+86-21-62489821$ 
(C) 2012 The Author(s). Licensee IntechOpen. This is an open access article distributed under the terms of the Creative Commons Attribution 3.0 License, which permits unrestricted use, distribution, and reproduction in any medium, provided the original work is properly cited. 